\title{
Perceived benefits of science park attributes among park tenants in the Netherlands
}

\author{
Wei Keat Benny $\mathrm{Ng}^{1}$ (D) $\cdot$ Robin Junker $^{1} \cdot$ Rianne Appel-Meulenbroek $^{1}$. \\ Myriam Cloodt ${ }^{1} \cdot$ Theo Arentze $^{1}$
}

Published online: 28 June 2019

(C) The Author(s) 2019

\begin{abstract}
Science parks as area developments have existed for decades and captivated the attention of academia and policy-makers for their potential impact on firms and regions. Only limited attention is given to the needs of science park firms regarding what science parks offer. Therefore, this study focused on science park facilities and services and how firms perceive the benefits associated with these attributes. An online survey distributed among tenants on seven science parks in the Netherlands yielded 103 respondents. An a priori list of science park attributes was presented in order to gain insight in how the respondents associated these facilities and services with potential benefits. The benefits considered were derived from proximity and innovation literature within the science park context. In general, science park attributes were associated with either proximity benefits or benefits related to the SP real estate. Based on a cluster analysis of organisational characteristics three tenant types were identified. The three tenant types sought different benefits through different attributes. Commercially-orientated firms associated science park attributes as ways for being near customers. Mature science-based firms associated attributes with a wider range of benefits, such as image benefits, being near customers and other firms. Young technology-based firms were more cost-driven and focused on image benefits. The associations between various types of facilities and the benefits that tenant types seek, provide insights for practitioners in terms of the design and management of science parks and add to the body of knowledge of science parks within the context of innovation management.
\end{abstract}

Keywords Science parks $\cdot$ Perceived benefits $\cdot$ Facilities and services $\cdot$ Real estate

JEL Classification O3 $\cdot \mathrm{L} 2$

Wei Keat Benny Ng

w.k.b.ng@tue.nl

1 Eindhoven University of Technology, P.O. Box 513, 5600 MB Eindhoven, The Netherlands 


\section{Introduction}

Science parks (hereafter SPs) are commonly described as physical areas where multiple knowledge-intensive organisations and institutes co-locate and where innovation is formally and informally leveraged (Link and Scott 2015). Through decades of SP development their main mission varies from fostering collaboration between university and industry, to regional development and ultimately increasing the efficiency of innovation (Bigliardi et al. 2006). From a policy perspective, SPs are supply-driven measures that aim to improve networking and collaboration between park tenants (Edler and Georghiou 2007). On macro-level, they mainly address market failures in terms of encouraging R\&D to take place at selected locations (Appold 2004). On micro-level, hosted firms share facilities and services, which allows them to avoid large capital investments in expensive facilities, optimise use and promote synergy (Brinkø et al. 2014; Van Winden and Carvalho 2015). In addition, co-location of various firms and, if present, universities provides for proximity benefits, such as knowledge sharing between tenants (National Research Council 2009; Ferrara et al. 2015).

Although SPs have captivated the attention of academia for decades, the body of knowledge on the concept remains embryonic and most of the empirical work has a limited geographical scope by focusing primarily on the UK and China (Hobbs et al. 2017). Existing SP research has mainly focused on the evaluation of the impact of SPs on firms in order to prove their policy effectiveness, but with limited conclusive evidence. Only uniform evidence of increased networking and collaboration between firms has been found, while little evidence is found for increased economic output (Albahari et al. 2010). According to Mora-Valentín et al. (2018) the current conceptual framework of SPs allows for more research to be done in the development of SPs.

Strikingly, little SP research is aimed at the needs of tenants in terms of the SP facilities and services (Albahari et al. 2018). Van Dierdonck et al. (1991) studied the perceived benefits of Dutch and Belgian SP firms during a period where SPs bridged the gap between academic science and industrial technology. Westhead and Batstone (1999) explored the perception of managed SPs and concluded that they should strengthen their managerial effort to show that these parks are more than a real estate proposition. From the perspective of university administrators, the perceived impact of SPs on attaining academic missions was studied by Link and Scott (2003). Nowadays, some form of management is present at the majority of SPs in Europe ( $\mathrm{Ng}$ et al. 2019). Moreover, the provision of management expertise and potential venture capital show that SPs have further developed beyond real estate (Etzkowitz and Zhou 2017). Managing the community of firms and shared resources and facilities on SPs is expected to create value on firmand park-level (Van Der Borgh et al. 2012). Albahari et al. (2018) revealed that configuration and process gaps (i.e. respectively facilities and services) between supply and needs are acknowledged by SP managers as troublesome. This mismatch deviates them from achieving policy goals, affects current tenant firms' performance negatively and repels potential new tenants. As SPs are commonly funded partially by public sources there is a sense of responsibility for proper resource allocation for current and future SP projects (Monck and Peters 2009). Research into the perception from the user side of SPs is therefore a first step into understanding how SPs create value for their tenants (Albahari et al. 2018). Insights on the perceived value of different facilities and service levels contributes to more effective SPs that in turn could promote the overall performance of the park and its wide range of tenants. 
Furthermore, as firms may differ regarding those needs and the SP impact, the diversity of tenants should be taken into account to obtain a clear insight in the needs of possible subgroups. Previous research suggests that SP impact varies among different types of firms (e.g. Díez-Vial and Fernández-Olmos 2015; Ubeda et al. 2019). So far, the majority of evaluation research has focused solely on start-ups (e.g. Fukugawa 2006; Yang et al. 2009; Chan et al. 2010; Löfsten 2016), although SPs are also home to established firms, research institutes and service providers (Van Der Borgh et al. 2012). Ferguson and Olofsson (2004) revealed that park firms have a wide range of maturity phases, which suggests that different needs are required to induce growth for starting and for more developed firms. For example, smaller and younger firms experienced more benefits from the SP image and the collaboration with universities than older and larger firms (Ferguson and Olofsson 2004). Moreover, Chan and Lau (2005) showed that even among start-ups within various business development phases different benefits were important within their incubator program on SPs.

The current study's novel contribution to the SP literature is to provide insight on the associations made by SP tenant firms in the Netherlands between perceived benefits and the provided facilities and services, whilst taking into account for the possible tenant types. Therefore, the research question addressed in this study is: which benefits do SP tenant firms associate with SP attributes (i.e. facilities and services) and does this perception differ among tenant types? The objective of this paper is to reveal the associations tenants make between a priori-defined facilities and services and specific SP benefits. It is based on a survey of 103 SP tenants in the Netherlands.

This study adds to the innovation policy management and SP knowledge base both in a scientific and a practical way. For further conceptualisation of the SP, this study sheds light on the link between what a SP offers and what value it brings to the different types of tenant firms. Insights into perceived benefits leads to a better understanding of how SPs impact tenants. For the design and management of SPs, the inclusion of specific facilities and services can be aspects to be considered as means to create value and to affect the overall performance of the SP itself or its tenants. In order to answer the research question, first the potential benefits are retrieved from literature. Then the research approach is explained in more detail in Sect. 3. The sample of SP tenant firms and the analysis of associations between attributes and benefits are examined in Sect. 4. Finally, in Sect. 5 the major conclusions and possible future research directions are discussed.

\section{Theoretical background}

SPs are composed of facilities and services that are aimed at innovation policy goals (Albahari et al. 2018). That some of these goals are not met due to the misalignment of the SP real estate and services has been coined innovation incommensurability (Etzkowitz and Zhou 2017). As SPs can be configured in various ways to attain different missions, goals and functions, evaluating them is a complex task (Capello and Morrison 2009). Consequently, the present paper is focused on the needs of SP users, to reveal which benefits SP tenants associate with the offered facilities and services. These perceived benefits could complement traditional performance measures as these indicators might not apply to all SP firms (Lecluyse et al. 2018). The following sections review the literature to provide an overview of the benefits tenant firms might perceive. Each of the seven subsections consist of one perceived benefit; (1) knowledge sharing and collaboration, (2) proximity of 
university, (3) proximity of firms in similar sectors, (4) proximity of markets and customers, (5) liveability of the site, (6) image and prestige of the site and (7) cost of accommodation and services.

\subsection{Knowledge sharing and collaboration}

Essentially, SPs are developed to promote interaction or networking through proximity between actors and to promote industrial activity and ultimately innovation (Edler and Georghiou 2007). The underlying mechanisms of localised knowledge spill-overs among co-located firms and institutions are believed to enhance invention and innovation (Lee and O’Huallachain 2012).

In general, geographical proximity contributes to, amongst other, cost reduction, increased personal interaction and development of social networks and therefore it aids knowledge transfer (Rosenkopf and Almeida 2003). Previous research showed that firms where corporate or academic R\&D and high-skilled labour is essential, are more likely to concentrate geographically. Co-location of innovating firms and academia contributes in some way to the circulation of information among those involved (Storper and Venables 2004). Besides geographical proximity, other types of proximity are likely to influence knowledge transfer between actors as well (Boschma 2005). These include cognitive, organisational and social proximity, where too much or too little proximity hinders knowledge transfer.

From a social proximity perspective, unplanned knowledge transfer on park-level is characterised by non-pecuniary and informal interactions. Social proximity is largely based on repeated interactions and trust (Boschma 2005). This is in contrast to knowledge trade, which is often facilitated by technology transfer offices through licensing, spin-offs or contract research (Villasalero 2014). Moreover, Storper and Venables (2004) argued that sharing difficult to codify, tacit knowledge and the stimulation of innovation is only possible through a high social proximity between actors and the subsequent face-to-face interactions. The degree of interaction (i.e. through face-to-face or virtual contact) and proximity among both parties' knowledge bases is key for the success of knowledge transfer (Cummings and Teng 2003). Díez-Vial and Fernández-Olmos (2015) argued that repeated formal and informal collaboration with universities allow firms to increase their absorptive capacity. This capacity of identifying value, assimilation and commercialisation of ideas enables organisations to utilise external knowledge sources more efficiently (Cohen and Levinthal 1990). Firms with high absorptive capacity benefit less from SPs as their knowledge bases might be too similar to others (Ubeda et al. 2019). Tacit knowledge, which is often complex knowledge, is more easily shared among strong ties, while well-documented knowledge is benefited by weak ties (e.g. Hansen 1999; Byosiere et al. 2010). Socialisation among actors on SPs enhances tie strength and therefore eases the transfer of valuable tacit knowledge (Inomata et al. 2016).

\subsection{Proximity of university}

Dettwiler et al. (2006) inquired start-ups on the importance of geographical proximity benefits, distinguishing nearness to a university, to customers and to firms (both competing and similar types). The proximity of a university was most valued, followed by customers and lastly firms whereby competing and similar firms were equally important. Ferguson 
and Olofsson (2004) also found that start-ups valued the cooperation with a university relatively more than access to new customers.

Industrial R\&D activity that is closely located to the university shows on a state-level higher numbers of corporate patents (Jaffe 1989). On firm-level, Romijn and Albu (2002) showed that start-ups that reported geographical proximity benefits to universities or laboratories tended to have more and/or complex innovations and also a higher number of held patents. Audretsch and Lehmann (2006) argued that small and medium-sized enterprises choose to locate near universities for the potential access to research and human capital. In the U.S., SPs more closely located to research universities were found to be growing faster in the number of firms, but this was unrelated to the presence of incubators (Link and Link 2003).

\subsection{Proximity of firms in similar sectors}

Organisational proximity is defined as the similarities in control and management of each involved actors' respective organisation (Boschma 2005). From an organisational perspective Chan and Lau (2005) argued that as SPs co-locate firms who are active in various parts of the value chain, these firms are likely to find suitable partners for collaboration both downstream and upstream. SPs, and if present incubators, play a pivotal role as intermediaries to reduce uncertainty and promote knowledge transfer for younger firms (Fukugawa 2013). However, McAdam and McAdam (2008) argued that as firms mature and competition rises, the willingness to share ideas and knowledge and collaborate on problemsolving will likely decrease. For firms in more matured industries the close proximity for knowledge benefits can be less apparent as knowledge is likely to be more codified and standardised, which limits the need for co-location for sharing tacit knowledge (Díez-Vial and Fernández-Olmos 2017).

From a cognitive proximity perspective, Koçak and Can (2014) revealed that knowledge sharing ties were most commonly followed by joint project or product development ties and that these ties were even more frequent when firms were active in similar industries. Therefore, SPs attempt to select similar firms based on technologies or sectors in order to promote synergy among them (Van Winden and Carvalho 2015). On the one hand, sufficient cognitive proximity between firms contributes to organisational learning (Gilsing et al. 2008). On the other hand, co-location can be disadvantageous as it also leads to knowledge spill-overs towards competing firms that are cognitively close to each other (Díez-Vial and Fernández-Olmos 2017). Therefore an optimal cognitive distance is required for mutual understanding and innovation (Van Gilsing et al. 2008). The need for a moderate overlap between knowledge bases underscores the need for a mix of organisation types on SPs that results in mutual learning.

\subsection{Proximity of markets and customers}

The geographical proximity of markets and customers provides means for firms to achieve their commercial goals, attain information on market demand and optimise their products or services (Lindelöf and Löfsten 2003). Capello and Morrison (2009) argued that interactions with customers should be both stable and intense and could lead to incremental innovations. However, Romijn and Albu (2002) did not find significant innovation benefits through networking activities of young firms with customers. Similarly, firms located on or off science parks that experienced high benefits from proximity of customers also did 
not show significant different growth rates (Ferguson and Olofsson 2004). Albahari et al. (2016) suggested that younger firms experience a positive effect of novelty, which attract customers on the short-term, but diminishes over time.

\subsection{Liveability of the site}

According to Kharabsheh (2012) both SP managers and park tenants value the high-quality landscaped environment, facilities and services as means to accommodate their employees and clients. As property initiatives, SPs provide both private space and public space for universities, firms and institutes. The landscaped public area can be vibrant and green with a high level of quality of environment (Zhang 2002; Wang and Adolphe 2012). Nature and green are often associated with positive psychological effects for work environments (Oseland 2009; Jahncke et al. 2011). Recent studies on greenspace at SPs revealed that the use of greenery and seeing greenspaces from indoor workplaces contribute to the wellbeing of employees and alleviate job stress (Gilchrist et al. 2015; Colley et al. 2017).

\subsection{Image and prestige of the site}

Besides liveability, the high quality landscaped park environment relates to image and reputation benefits of both the SP and its tenants (European Commission 2013). Especially for start-ups, a SP can provide legitimacy and overcome their role as new entrants (Ferguson and Olofsson 2004). According to Van Dierdonck et al. (1991) only a minority of their responding firms on Dutch and Belgian SPs perceived the access to scientific or technological resources at universities to be the most important location factor. In contrast, image of the site, modes of transportation and financial incentives were the most important for tenant firms to choose a SP. Chan et al. (2010) revealed that firms mainly located on SPs for improving their reputation and image, which is perceived as commercially beneficial, while less for networking or knowledge sharing. However, Ferguson and Olofsson (2004) showed that perceived image benefits alone are insufficient for stimulating growth or survival for start-ups. Furthermore, dedicated facilities and services with shared reception services make them appear more professional (Chan and Lau 2005; McAdam and McAdam 2008; Van Der Klundert and Van Winden 2008).

\subsection{Cost of accommodation and services}

Within the park environment, facilities, such as laboratories, meeting rooms, conference rooms and sport facilites are designated for both private use and shared usage among different tenant firms ( $\mathrm{Ng}$ et al. 2019). Specifically, for start-ups, specialised R\&D facilities, equipment, offices, business support, training programs, networking events, dining facilities, venture capital access are usually part of the shared facilities and services within incubator premises (McAdam and McAdam 2008). Moreover, the large range of SP facilities and services enable especially start-ups to focus on their core activities (Aaboen 2009; Dabrowska 2016). Often, rented facilities and the use of park services that are shared between firms can reduce costs among park firms (Brinkø et al. 2014). However, according to Westhead and Batstone (1999) accommodation costs were named one of the most important disadvantages of SPs and even more so for firms on non-managed parks. They 
Table 1 SP benefits and attribute

\begin{tabular}{|c|c|c|}
\hline \multicolumn{2}{|l|}{ Labels } & Benefits \\
\hline Knowledge & & Knowledge sharing and collaboration \\
\hline University & & Proximity of university \\
\hline Firms & & Proximity of firms in similar sectors \\
\hline Customers & & Proximity of markets and customers \\
\hline Liveability & & Liveability of the site \\
\hline Image & & Image and prestige of the site \\
\hline Cost & & Cost of accommodation and services \\
\hline Labels & Attributes & Examples \\
\hline $\mathrm{R} \& \mathrm{D}$ & $\mathrm{R} \& \mathrm{D}$ facilities & Laboratory, clean room, piloting room \\
\hline Equipment & Equipment & 3D printer, autoclave, centrifuge \\
\hline Specials & Specials & Particle accelerator, wind tunnel, joint permits \\
\hline Workspace & Workspace & Conference centres, co-working space, meeting rooms \\
\hline Business support & Business support & ICT support, administrative, consultancy \\
\hline Training & Training programs & Incubator programs, workshops, lectures \\
\hline Park management & Park management & Maintenance, cleaning, safety, security \\
\hline Information & Information access & Library, network platform, databases \\
\hline Venture capital & Venture capital access & Legal and finance agencies, investment funds \\
\hline Networking & Networking events & Conferences, symposium, business courses \\
\hline Social & Social events & Concerts, marathons, food festivals \\
\hline Dining & Dining facilities & Restaurant, cafeteria \\
\hline Residential & Residential facilities & Hotel, residential housing \\
\hline Leisure & Leisure facilities & Cinema, sports facilities, wellness, shops \\
\hline Additional & Additional facilities & Expat centre, day care, car share service \\
\hline
\end{tabular}

found that while groups valued the offered services and the park image, they were reluctant to pay the premium prices.

In conclusion, on the user-side, the benefits SP tenants see regarding attributes SPs offer as emerged from this literature review, are: (1) knowledge sharing and collaboration, (2) proximity of markets and customers, (3) proximity of university, (4) proximity of firms in similar sectors, (5) liveability of the site, (6) image and prestige of the site and (7) cost of accommodation and services. On the supply-side, fifteen SP attributes are distinguished, which are adopted from previous research on SP attributes (i.e. $\mathrm{Ng}$ et al. 2019). The list of attributes and benefits that are used in this study are listed in Table 1.

\section{Data and methods}

\subsection{Sampling procedure}

An online survey was designed and distributed through management teams of SPs among the decision-makers (i.e. CEO or manager) of park tenants in the Netherlands. As they all are located in the Netherlands, respondent firms were expected to be exposed to similar climate, culture and institutions (Acs et al. 2013). To be eligible for this research, SPs 
had to meet the following criteria: a physical location with multiple buildings, presence of a research institute or university, a professional management team and shared facilities and services. The management teams of seventeen eligible SP locations were contacted and ultimately seven participated. This top-down approach was chosen as management teams have close contacts with tenants. The survey was distributed between September and November of 2017 among 565 tenant firms that were contacted through their respective SP management.

\subsection{Measurement}

The first section of the survey involved questions on personal and general organisational information. Specifically, respondents were shown the new product development (hereafter NPD) funnel, consisting of (1) concept development, (2) design and engineer, (3) prototyping and testing and (4) launch (Dahan and Hauser 2002). Each phase was described and respondents were asked which if any of the phases was applicable for their firm. Furthermore, respondents selected one or more of the 21 sectors in which their firm is active. In the second section respondents indicated which of the fifteen predetermined SP attributes were offered on their location. In the final section of the survey, the seven SP benefits were presented (see Table 1 for the attributes and benefits). First, respondents were asked independently from the attributes, which two of the listed SP benefits were most important in choosing their SP location. For the remainder of this paper, these benefits without being related to specific SP attributes are referred to as principal benefits, as they are important for tenants in a general sense. Then, the fifteen attributes were presented separately and respondents indicated which (if any) benefits they most strongly associate with the presented attribute. This quantitative approach of collecting association data is adapted from the association pattern technique (Ter Hofstede et al. 1998). That technique presents predetermined attributes, benefits and values of a product to consumers and aims to gain insight in their needs. The attributes embody "what" consumers choose, while benefits that are associated with these attributes are "why" they chose them (Dellaert et al. 2014). Moreover, it allows for analysis techniques from association rule learning based on conditional and unconditional probabilities of attributes and benefits (Tan et al. 2006). In this manner, respondents chose a maximum of the two most important benefits that they deemed related to each attribute. When a respondent did not associate any benefit to a specific attribute, the option of not applicable was selected. Therefore, the associations for a specific attribute are established by eight binary variables ( 7 benefits and the not applicable option). The selection of not more than two benefits enforced prioritisation and relieved pressure for respondents during their completion of the survey by not asking them to rank all benefits each time.

\subsection{Analysis method}

The analysis was twofold; first the Twostep clustering algorithm was used to distinguish meaningful subtypes of the sample based on organisational characteristics. This clustering technique was more appropriate for this dataset than k-means or hierarchical clustering as it handles both continuous and categorical variables and the number of clusters were not known beforehand (Norušis 2011). In the first step of the algorithm, pre-clusters were constructed based on log-likelihood measures, while in the second step the optimal number of clusters were formed based on either the Akaike information criterion or the Bayesian 
information criterion. Either criterion should be as low as possible to indicate a more fitting model, while the distance measure should be as high as possible. Furthermore, this method produced a cohesiveness ratio ranging between -1 and +1 , where a higher value indicated larger differences between clusters and more similarities within clusters. A cluster ratio of 0.2 or higher is considered fair (Mooi and Sarstedt 2014). Furthermore, each selected variable, which largely determined cluster membership was assigned a predictor value between 0 (unimportant) and 1 (very important). Tkaczynski (2017) argued that while cluster variables with predictor value of 0.02 or lower can be used, this would ultimately result in similar values across those cluster variables.

The second part of the analysis considered the associations respondents established between the attributes and benefits. In this part, the observations $(n)$ were the associations between attributes and benefits. The fifteen attributes (A) were presented to respondents in order to gauge which if any of the seven benefits (B) were associated with each particular attribute. A not applicable option was included for attributes where no benefits were found relevant by respondents. This approach led to two sets of observations; the selection of relevant attributes and associations of benefits with the selected attributes. These observations allowed for the following three analyses procedures.

First, a Chi-square test of goodness-of-fit was conducted to analyse the associations between attributes and benefits. The inclusion of the not applicable (towards a benefit) option revealed the relevance of the attributes; hence a first test considers whether the selection of the not applicable option is significantly different for the attributes from equal probabilities. Next for the remaining analyses, the not applicable option was excluded in order to focus on the benefit associations. The same test was done for each attribute to find if the observed selection frequencies of seven benefits differed significantly from the expected probability if no associations exist (the marginal probability of each benefit).

Secondly, based on the association data the probability was determined for each $B_{j}$ separately, that the benefit is mentioned in the context of some attribute, denoted as $P\left(B_{j}\right)$, where $j$ is one of the seven benefits. The probability that $B_{j}$ is mentioned in the context of a specific attribute $A_{i}$, is given by the conditional probability $P\left(B_{j} \mid A_{i}\right)$, where $i$ is one of the fifteen attributes. It follows, that if the probability of $B_{j}$ is not associated with the attribute $A_{\mathrm{i}}$, the expected ratio $(I)$ between the conditional and unconditional probability is equal to one or lower. Its occurrence probability is the same as the unconditional probability $(I=1)$ or reduces when $A_{i}$ is given $(I<1)$. A ratio larger than one indicates that $B_{j}$ is associated with $A_{i}$ (its occurrence probability increases when $A_{\mathrm{i}}$ is given). The ratio $(I)$ is known as the lift ratio in the marketing and data-mining literature. The lift ratio is more informative than $P\left(B_{j} \mid A_{i}\right)$ as the latter does not take into account the base probability of $B_{j}$ and therefore does not reveal attributes and benefits that are not associated (i.e. $I \leq 1$ ) (Tan et al. 2006). Formally, the lift ratio is defined as:

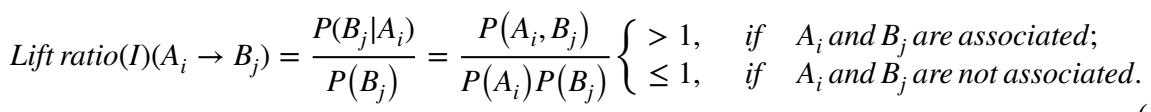

Moreover, the equation of the lift ratio is somewhat similar to the Chi-square equation as both calculate the ratio between the observed and the expected values. The lift ratio reveals the strength and the direction of the association between $A_{i}$ and $B_{j}$, while the Chisquare value shows if the vector of benefit-associations with the attribute is significantly different from expected values. On attribute level, each $A_{i}$ could be associated with seven $B_{j}$. Therefore, in the Chi-square test, each attribute is treated as a vector with six degrees 
of freedom. Associations of attributes $A_{i}$ that turn out to be significant are reported and discussed. Lastly, the association of the different clusters of organisation types were further explored. A Chi-square test of goodness-of-fit was conducted to test if the seven benefits are equally associated by the three clusters of tenant types. Then on attribute level, the lift ratios were calculated for each cluster separately and compared to show possible differences among the most associated benefits.

\section{Results}

\subsection{Sample description}

From the seventeen SPs, seven parks were willing to distribute the survey among their tenants. In total 103 representatives of tenant firms completed the survey (response rate $18 \%$ ). The distribution of respondent firms among the seven SPs is not representative as significant differences are found between the sample and the contacted population firms $\left(\chi^{2}(6)=22.93, p<0.001\right)$. Table 2 summarises the characteristics of the sample. The majority of respondents were either a director or manager of their firm and worked either in general management $(53 \%)$ or $\mathrm{R} \& \mathrm{D}$ (23\%), which shows that the sample indeed consisted mainly of decision-makers active in relevant departments.

In order to check for non-respondent bias, the procedure of Armstrong and Overton (1977) was used. This method compares the first half (in time of completing the survey) with the last half of the respondents on possible similarities among organisational characteristics. It is assumed that the latter group is relatively less interested in completing the survey, which resembles non-respondents more closely. The respondents were divided in two groups and tests of significant differences were conducted with size on park, firm age, duration of stay and high sectoral focus. ${ }^{1}$ A significant difference was only found on firm age between the two subsamples $(\mathrm{t}(103)=2.649, p=0.009)$, the latter being younger than the former, which suggests there is little non-response bias.

\subsection{Distinguishing organisation types}

Based on the sample size of 103 , a conservative number of six cluster variables was used. The minimum sample size should equal $2^{\mathrm{m}}$, where $m$ is the amount of variables to be considered (Formann 1984). The six chosen cluster variables from Table 2 were (1) technology industries, (2) trade, sales, marketing and construction, (3) NPD funnel, ${ }^{2}$ (4) size on park, (5) scientific research and (6) duration of stay on park. These variables were chosen in order to differentiate tenant types and compare their needs more adequately. Duration of stay on park is opted for clustering over firm age as both variables were correlated $(\mathrm{r}(103)=0.284, p=0.004)$ and the length of stay was expected to be more impactful on the SP needs than the age of the firm (Liberati et al. 2016). Multiple

\footnotetext{
1 The 21 dummy variables of technology sectors were transformed into a continuous variable in order to find a median of 2, which functioned as a cut-off point to split the sample into 64 firms with a high sectoral focus (1 or 2 sectors) and 39 with a low sectoral focus (more than 2).

2 Cronbach's $\alpha$ for the four binary variables of NPD phases was sufficient reliable with 0.703 for exploratory studies (Chan et al. 2010). Therefore the continuous construct NPD funnel was created which ranged between 0 and 4 with an average value of 1.95 and a standard deviation of 1.46.
} 
Table 2 Characteristics of 103 SP tenant firms

\begin{tabular}{|c|c|c|c|c|c|}
\hline & \multicolumn{3}{|c|}{ Mean } & \multicolumn{2}{|r|}{$\mathrm{SD}$} \\
\hline Firm age (years) & \multicolumn{3}{|c|}{26.32} & & 36.78 \\
\hline Duration of stay on park (years) & \multicolumn{3}{|c|}{7.88} & \multicolumn{2}{|r|}{10.5} \\
\hline & $\mathrm{n}$ & $\%$ & & $\mathrm{n}$ & $\%$ \\
\hline Size on park (employees) & & & NPD funnel (phases) ${ }^{\mathrm{a}}$ & & \\
\hline Less than 10 & 50 & 48.54 & Concept development & 46 & 19.28 \\
\hline Between 10 and 50 & 32 & 31.07 & Design and engineer & 56 & 25.11 \\
\hline Between 50 and 250 & 13 & 12.62 & Prototyping and testing & 54 & 24.22 \\
\hline \multirow[t]{2}{*}{ More than 250} & 8 & 7.77 & Launch & 48 & 21.52 \\
\hline & 103 & 100.00 & Not applicable & 22 & 9.87 \\
\hline Sectors $^{\mathrm{a}}$ & & & Activity $^{\mathrm{a}}$ & & \\
\hline Biotechnology/life sciences & 28 & 9.69 & Technology industries & 52 & 50.49 \\
\hline Industrial/manufacturing systems & 25 & 8.65 & Scientific research & 32 & 31.07 \\
\hline Software & 24 & 8.30 & Manufacturing & 31 & 30.10 \\
\hline IT/telecommunications & 22 & 7.61 & Education and training & 25 & 24.27 \\
\hline Industrial electronics & 20 & 6.92 & Engineering services & 23 & 22.33 \\
\hline Internet technologies and services & 18 & 6.23 & Value-added services & 20 & 19.42 \\
\hline Computer/informatics & 17 & 5.88 & $\begin{array}{l}\text { Trade, sales, marketing } \\
\text { and construction }\end{array}$ & 13 & 12.62 \\
\hline Energy technology & 16 & 5.54 & Corporate office & 12 & 11.65 \\
\hline Environmental technology & 13 & 4.50 & Other & 7 & 6.80 \\
\hline Chemistry & 12 & 4.15 & & & \\
\hline Nanotechnology & 12 & 4.15 & & & \\
\hline New materials & 12 & 4.15 & & & \\
\hline Consumer electronics & 9 & 3.11 & & & \\
\hline Pharmaceuticals & 9 & 3.11 & & & \\
\hline Off-shore technology & 7 & 2.42 & & & \\
\hline Agro-food/agriculture & 6 & 2.08 & & & \\
\hline Food technology & 6 & 2.08 & & & \\
\hline Optics & 6 & 2.08 & & & \\
\hline Aeronautics/aerospace & 4 & 1.38 & & & \\
\hline Sports technology & 3 & 1.04 & & & \\
\hline Other & 20 & 6.92 & & & \\
\hline
\end{tabular}

${ }^{\mathrm{a}}$ Respondents were allowed multiple options

cluster solutions were generated varying the number of clusters and the final solution was based on the criteria of a relatively high cohesive coefficient and a relatively high value for the weakest predictor. In Table 3 distance measures are shown for solutions with a varying number of clusters. The auto clustering of the Twostep clustering algorithm resulted in an eight cluster solution based on the AIC criterion and a six cluster solution based on the BIC criterion. In order to avoid many small clusters the three cluster solution was selected as this solution had the highest ratio of distance measure (1.405) and an equally high silhouette coefficient compared to the other cluster solutions $(0.3)$. 


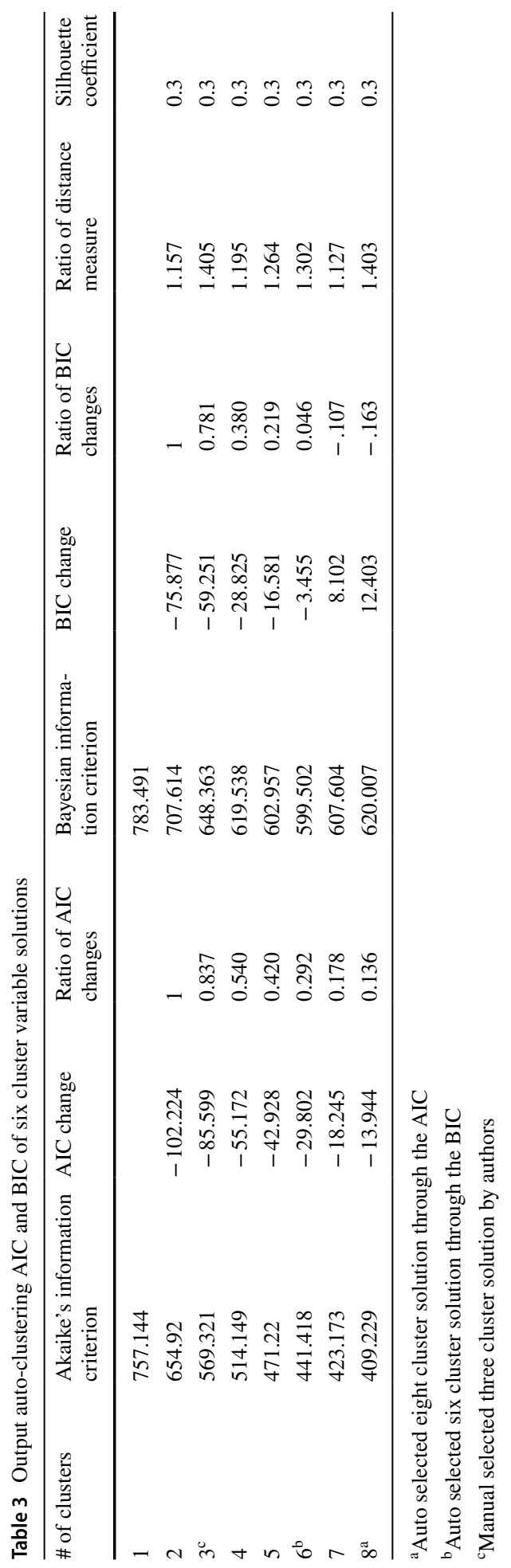




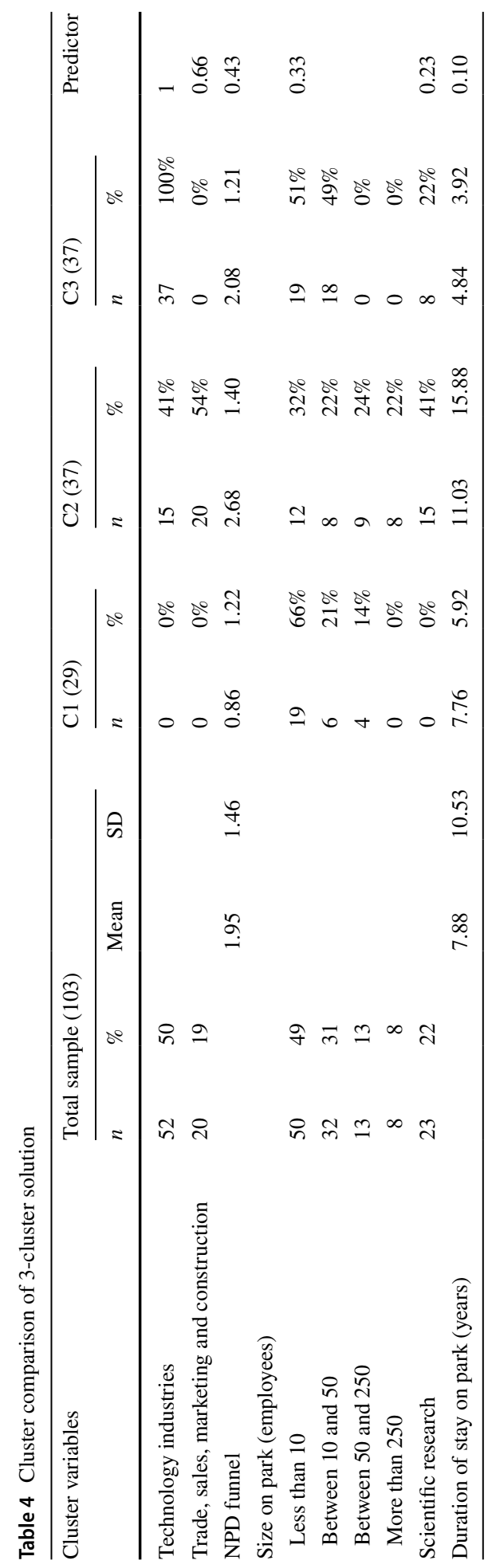


The final cluster solution is shown in Table 4 with the total sample and the three sub clusters. The three clusters were labelled (1) commercially-oriented firms, (2) mature science-based firms and (3) young technology-based firms. The order of cluster variables in Table 4 is based on the predictor values, where a higher value indicates a higher importance for characterising the clusters.

The clusters can be interpreted as follows.

\subsubsection{Commercially-oriented firms (C1)}

This cluster is not active in technology industries and none of the firms are active in trade, sales, marketing and construction activities. Consequently, this group is relatively less active within the phases of the NPD funnel and none of these firms conduct scientific research. Firms are mainly small-sized. Relatively, this group has remained on SPs for a long period. Subsequent tests reveal that firms in this cluster are significantly more active in IT/Telecommunications (34\% for cluster members versus $16 \%$ for non-members, $p=0.041$, Fisher's exact test). In contrast, they are significantly less active in Biotechnology/Life Sciences compared to others (7\% vs. $35 \%$ respectively, $p=0.002$, Fisher's exact test).

\subsubsection{Mature science-based firms (C2)}

This cluster is largely not active in technology industries and a slight majority are active in trade, sales, marketing and construction activities. This group is highly active within all the phases of the NPD funnel and therefore a number of these tenants also conducts scientific research. With regard to firm size all categories are present. Relatively, this group has been on SPs for the longest period.

\subsubsection{Young technology-based firms (C3)}

Firms in this cluster are all active in technology industries and none are active in trade, sales, marketing and construction activities. This group is in terms of the NPD funnel phases moderately active and the majority does not conduct scientific research. Firms are either small or medium-sized. Relatively, this group has stayed on SPs for the shortest period. As a result of their size, young technology-based firms are in comparison to the second group less active in the NPD funnel. This is in line with the reasoning that in general smaller firms are less capable in covering all phases necessary to complete and launch innovations (Brunswicker and Vanhaverbeke 2015).

\subsection{Importance SP attributes and perceived benefits}

Table 5 shows the conditional probabilities of the benefits for each given specific attribute. Respondents selected the option not applicable (N/A) for attributes that were irrelevant for them. In general, the majority of attributes was associated to one or more benefit(s); only $8 \%$ (113) of all attributes had no benefits associated to them.

A Chi-square test of goodness-of-fit showed that the not applicable option is not equally distributed across the fifteen attributes. The SP firms in this sample associated attributes and the N/A option significantly different from the expected probabilities, $\chi^{2}$ $(14, n=1469)=44.58, p<0.000$. This reveals that the importance of attributes is unequal 


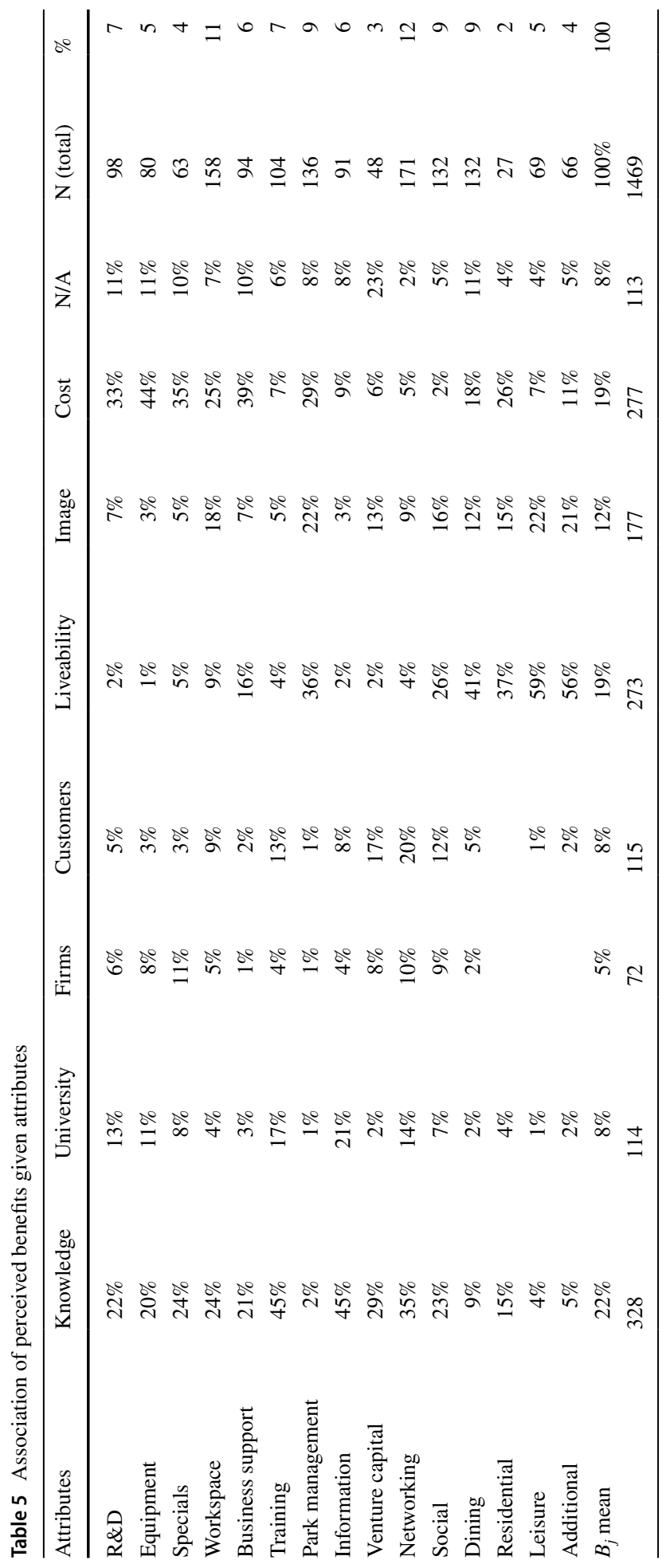


Table 6 Frequency of principal benefits and rank order based on association with attributes

\begin{tabular}{lll}
\hline Benefit & $\%$ & $\begin{array}{l}\text { Rank in } \\
\text { associa- } \\
\text { tion }\end{array}$ \\
\hline Knowledge sharing and collaboration & 21 & 1 \\
Proximity of university & 20 & 6 \\
Proximity of firms in similar sectors & 14 & 7 \\
Image and prestige of the site & 14 & 4 \\
Proximity of markets and customers & 11 & 5 \\
Cost of accommodation and services & 11 & 2 \\
Liveability of the site & 4 & 3 \\
Others & 4 & - \\
$n=187$ & & \\
\hline
\end{tabular}

according to SP firms. Excluding the N/A option, the selection of six out of the seven identified benefits is not equal to the expected equal probabilities $\left.\chi^{2}(6, n=1356), p<0.000\right){ }^{3}$ Only the image benefit is not significantly different from random chance, which suggests that this benefit is not associated to any attributes in specific. Respondents chose up to two benefits that they perceive as important for their organisation independent from SP attributes (hereafter principal benefits). Although respondents were allowed to select less than two or even zero principal benefits, only few did not select two options. Table 6 shows the principal benefits ordered on frequency in the first column and the rank order based on associations with attributes in the last column. The latter rank order is based on the total number of times each benefit is mentioned in the context of an attribute (the last row in Table 6). Knowledge and university were most frequently chosen. Followed by firms, image, customers and cost. The least chosen benefits were liveability and others. Open answers given by respondents for others were: shared marketing, expansion possibilities, access to professional networks, search for investors and specific $R \& D$ facilities. It is noted that some of these answers given by the respondents are not strictly benefits, but are more similar to attributes. This is not considered a major issue as the benefit others is selected only seven times across all respondents. Among all choices made, none of the principal benefits was chosen by the majority of the respondents, which shows the diversity of perceptions within the total group.

Knowledge sharing and collaboration was most frequently chosen as principle benefit and much less frequently in the context of attributes regarding facilities and services. In addition, both university and firms were frequently chosen principal benefits, but these two benefits were also far less often associated with such attributes (respectively, the sixth and seventh rank). In contrast, liveability and cost were associated with attributes more frequently, but were less chosen as principal benefits of a SP. The associations between the attributes and perceived benefits will be discussed more in-depth in the next section.

\footnotetext{
3 Selection of benefits compared to the marginal probability of benefits $\chi^{2}(6, n=1356)$; knowledge $\chi^{2}=113.51, p<0.000 ;$ university $\chi^{2}=26.40, p<0.000 ;$ firms $\chi^{2}=67.86, p<0.000$; customers $\chi^{2}=25.65$, $p<0.000$; liveability $\chi^{2}=43.50, p<0.000$; image $\chi^{2}=0.24, p=0.99 ;$ cost $\chi^{2}=47.48, p<0.000$.
} 
Table 7 Lift ratios attributes and benefits

\begin{tabular}{llllllll}
\hline Attributes & Knowledge & University & Firms & Customers & Liveability & Image & Cost \\
\hline R\&D & 1.05 & $\mathbf{1 . 7 8}$ & 1.30 & 0.68 & 0.11 & 0.62 & $\mathbf{1 . 8 0}$ \\
Equipment & 0.93 & $\mathbf{1 . 5 1}$ & $\mathbf{1 . 5 9}$ & 0.33 & 0.07 & 0.22 & $\mathbf{2 . 4 1}$ \\
Specials & 1.09 & 1.04 & $\mathbf{2 . 3 1}$ & 0.41 & 0.26 & 0.40 & $\mathbf{1 . 8 9}$ \\
Workspace & 1.07 & 0.49 & 1.02 & 1.12 & 0.47 & 1.46 & 1.30 \\
Business support & 0.97 & 0.42 & 0.22 & 0.28 & 0.88 & 0.63 & $\mathbf{2 . 1 3}$ \\
Training & $\mathbf{1 . 9 8}$ & $\mathbf{2 . 1 8}$ & 0.77 & $\mathbf{1 . 5 6}$ & 0.20 & 0.39 & 0.35 \\
Park management & 0.10 & 0.10 & 0.15 & 0.19 & $\mathbf{1 . 9 5}$ & $\mathbf{1 . 8 4}$ & $\mathbf{1 . 5 3}$ \\
Information & $\mathbf{2 . 0 2}$ & $\mathbf{2 . 6 9}$ & 0.90 & 0.98 & 0.12 & 0.27 & 0.47 \\
Networking & 1.49 & $\mathbf{1 . 7 1}$ & $\mathbf{1 . 9 2}$ & $\mathbf{2 . 4 7}$ & 0.18 & 0.73 & 0.26 \\
Social & 0.99 & 0.86 & $\mathbf{1 . 8 1}$ & $\mathbf{1 . 5 1}$ & 1.35 & 1.29 & 0.12 \\
Dining & 0.42 & 0.30 & 0.32 & 0.70 & $\mathbf{2 . 2 7}$ & 1.04 & 1.00 \\
Leisure & 0.19 & 0.18 & & 0.18 & $\mathbf{3 . 0 9}$ & $\mathbf{1 . 7 4}$ & 0.37 \\
Additional & 0.20 & 0.19 & & 0.19 & $\mathbf{2 . 9 2}$ & $\mathbf{1 . 7 0}$ & 0.54 \\
\hline
\end{tabular}

Bold indicates strong associations $(I>1.5)$, italics indicates not associated $(I<0.5)$

\subsection{Associations between attributes and benefits}

This study aims to reveal the link between SP attributes and perceived benefits. Therefore the instances of not applicable were not considered for the analysis of associations between attributes and benefits. This brings the sample on the level of associations to 1356 attribute-benefit pairs judged by the respondents. A Chi-square test for each of the fifteen attributes was done to determine if the observed counts between a specific attribute and benefit differs significantly from the expected probabilities. The expected probability of an $A_{i}-B_{j}$ association is the product of the $P\left(B_{j}\right)$ and the number of associations of $A_{i}$ (see "Appendix 1 ”). Relatively less often a benefit was selected for venture capital and residential attributes, which led to small observed and expected counts meaning that the Chi-square test was not applicable. Chi-square tests on the remaining thirteen attributes are all highly significant $(p<0.005)$ and these associations are further discussed.

The lift ratio $(I)$, where the conditional probability of a benefit given an attribute is divided by the overall probability of that benefit, was used to investigate the association strength between attributes and benefits. A lift ratio higher than one indicates an association between an attribute and a benefit. While a value of one or lower indicates that the benefit is not associated to the attribute. Table 7 lists the lift ratios of all attribute-benefit pairs. Two thresholds are chosen for emphasising interesting associations; for strong associations $(>1.5)$ and for pairs that are not associated $(<0.5)$.

Next, for each benefit, the most interesting associations are discussed.

Firstly, the knowledge benefit, which stands for knowledge sharing and collaborative opportunities, is most strongly associated with information access and training programs and, as expected, least associated for the more supporting facilities that a SP could offer. This benefit is also associated with business networking events, but is not associated with social events. Moreover, SP facilities (i.e. $R \& D$, specials, and workspace) are not associated with knowledge benefits. This suggests that the use of these facilities is not perceived to lead to mutual learning among different organisations. Secondly, proximity of university is associated with both research-related facilities and content-related services. The former 
Table 8 Associated benefits among clusters and total group

\begin{tabular}{lcccccccc}
\hline Cluster & Knowledge & University & Firms & Customers & Liveability & Image & Cost & Total \\
\hline Commercial & $18 \%$ & $7 \%$ & $6 \%$ & $14 \%$ & $22 \%$ & $15 \%$ & $18 \%$ & 384 \\
Mature science & $28 \%$ & $9 \%$ & $3 \%$ & $6 \%$ & $18 \%$ & $13 \%$ & $22 \%$ & 475 \\
Young technology & $25 \%$ & $9 \%$ & $7 \%$ & $6 \%$ & $21 \%$ & $11 \%$ & $21 \%$ & 497 \\
Total group & $24 \%$ & $8 \%$ & $5 \%$ & $8 \%$ & $20 \%$ & $13 \%$ & $20 \%$ & $100 \%$ \\
& 328 & 114 & 72 & 115 & 273 & 177 & 277 & 1356 \\
\hline
\end{tabular}

might suggest that the usage of these facilities allows tenants to be near academic staff. However, social events are not associated with university as SP firms are more interested on acquiring academic insights through information, training and networking events. The proximity of firms benefit is associated through the majority of the research-related facilities suggesting that there is some form of co-presence with other organisations at SPs. Furthermore, respondents associated the proximity of markets and customers benefit to the attributes business networking events, training programs and social events. On the other hand, it seems that within this sample dining facilities are not used abundantly for inviting clients to the SP. Similar to proximity of firms, both social events and networking events are beneficial to get near to clients (customers).

The liveability benefit, which is related to spatial quality, is most strongly associated with leisure, additional (i.e. bike repair shop, day care etc.), dining and park management. In contrast, the research and work-related facilities are not associated with liveability. Moreover, events within the context of business networking, such as conferences or seminars are not associated with liveability. While social events are somewhat associated with this benefit.

The image associations are to some extent similar to liveability. Respondents perceived image benefits to be related to park management, leisure and additional facilities. The research-related facilities are also not associated with image benefits. One exception is the association made with workspace, which could be related to the high-quality buildings commonly present on SPs.

Lastly, cost benefits are mainly associated with research and work-related facilities, business support and park management. These attributes are likely to be selected as a result of economies of scale derived from shared facilities and services. A large number of services are not associated with cost benefits. The attributes training, information, networking, social and leisure do not lead to some form of cost saving. These services are likely to be perceived as costly compared to their added value.

\subsection{Differences between tenant types in associations between attributes and benefits}

Each cluster of tenant firms was compared with the total group. Table 8 shows for each cluster the frequencies with which benefits are associated to attributes across all attributes. A Chi-square test was performed to determine if the (seven) benefits were selected with equal probabilities between the clusters. It turns out that commercially-oriented firms, mature science-based firms and young technology-based firms associate benefits significantly different from each other, $\chi^{2}(12, n=1356)=44.30, p<0.000$. 
Table 9 Most associated benefits with attributes per SP tenant type

\begin{tabular}{lllllll}
\hline & Commercial & & Mature science & \multicolumn{2}{c}{ Young technology } \\
\hline R\&D & University & $\mathbf{4 . 3 9}$ & University & $\mathbf{1 . 8 0}$ & Cost & 1.81 \\
Equipment & Firms & $\mathbf{2 . 5 7}$ & Cost & 2.61 & Cost & 2.18 \\
Specials & Firms & 4.17 & Firms & 2.83 & Firms & 1.70 \\
Workspace & Customers & $\mathbf{1 . 6 5}$ & Image & 1.68 & Cost & $\mathbf{1 . 4 1}$ \\
Business support & Cost & 2.65 & Cost & 2.21 & Cost & 1.65 \\
Training & University & 2.48 & Customers & $\mathbf{2 . 4 0}$ & University & 2.27 \\
Park management & Liveability & 1.80 & Image & $\mathbf{2 . 3 6}$ & Liveability & 1.89 \\
Information & University & 3.07 & University & 2.49 & University & 2.68 \\
Networking & Customers & 2.13 & Firms & $\mathbf{2 . 7 8}$ & Customers & 3.15 \\
Social & Firms & 1.71 & Firms & 2.89 & Image & $\mathbf{1 . 5 9}$ \\
Dining & Liveability & 1.85 & Liveability & 2.50 & Liveability & 2.44 \\
Leisure & Liveability & 2.70 & Liveability & 3.13 & Liveability & 3.52 \\
Additional & Liveability & 2.54 & Liveability & 3.46 & Liveability & 2.79 \\
\hline
\end{tabular}

Bold indicate most associated benefits that are different from the total group

Commercially-oriented firms associate attributes most often with liveability benefits followed by knowledge and cost. However, the frequency of these latter two benefits are somewhat lower compared to the other two clusters. Furthermore, commercially-oriented firms associate customers with attributes more frequently than the group average. Mature science-based firms associate knowledge and cost more than the group average, while this cluster selects firms less often than the other clusters. Young technology-based firms associate knowledge and cost benefits in similar fashion as mature science-based firms, although more attributes are associated with firms.

For each of the three clusters, the lift ratios $(I)$ are discussed in which the conditional probability of a specific benefit given a specific attribute was compared with the unconditional probability of that benefit. The conditional probabilities and lift ratios of all A-B associations broken down to commercially-oriented firms, mature science-based firms and young technology-based firms are found in "Appendices 2, 3 and 4".

Between the three tenant types no differences are found among the highest lift ratios for specials, business support, information, dining, leisure and additional attributes. In Table 9, for each attribute, the most associated benefits are listed per cluster based on the lift ratio. The bolded cells within the table indicate benefits that are associated by clusters that differ from the total group. Only nine attribute-benefit pairs are different from the total group, which suggests that the perceived benefits for attributes are quite consistent compared to the overall group.

Compared to the total group there are some differences among the clusters in the sample. Workspace is the only attribute that is associated by each tenant type to a different benefit. An explanation is that the total group did not associate workspace with a specific benefit strongly, which results in these different perceptions. For $R \& D$ the first two clusters associate this attribute the most strongly with university. It is important to note that the research-related attributes (i.e. $R \& D$, equipment and specials) are selected less often by commercially-oriented firms than the other two clusters. In contrast, one of the main benefits for this group is proximity of markets and customers as this is related to workspace and networking events, which are the most frequently chosen attributes (respectively $11 \%$ 
and $13 \%$ across all associations). For workspace, commercially-oriented firms are significantly more likely to select the customers benefit than firms of other clusters (23\% vs. $4 \%$ respectively, $p<0.001$, Fisher's exact test). For mature science-based firms the perceived benefit for training programs is to be near customers, while the other two clusters relate this attribute predominantly to university benefits. Furthermore, while park management is generally perceived to be contributing to the liveability of the SP, this cluster associates this service more towards image benefits. Likewise, mature science-based firms associate business networking events relatively more often to be near other firms than the other two clusters. Lastly, young technology-based firms differ from the others on cost benefits through workspaces and image benefits through social events.

\section{Discussion}

The results show that tenant firms on SPs in the Netherlands perceive different benefits from the different facilities and services attributes that SPs offer. Overall, both training programs and business networking events are associated by SP firms to proximity benefits (i.e. nearness to certain actors), while park management, leisure and additional facilities are more strongly related to liveability and image benefits (park management is also associated with cost saving). Important to note is that in the perception of tenants each attribute serves a specific purpose. Research-related facilities are an exception (i.e. $R \& D$, equipment and specials) as these attributes are associated to both proximity benefits and cost benefits.

This study expands past research on perceived benefits through the analysis of the conditional probabilities of these benefits given SP attributes and by taking into account the diversity among tenant types. Looking at the principal benefits, the most important ones are knowledge sharing and collaboration and proximity of university benefits, which is in line with previous work by Ferguson and Olofsson (2004) and Dettwiler et al. (2006), although in this study, the a priori selection of these two benefits was not heavily favoured over the other five benefits. Similar to the study of Van Dierdonck et al. (1991), the university was not the most important location aspect of SPs among all SP tenant firms and financial motives and the accessibility of the SP were also influential in their decision-making. This reveals that SP tenants are looking for a broad range of benefits a SP can offer. The option for own input besides predefined benefits from literature was given, but not used frequently by respondents.

First, the main contribution of this paper to the SP literature is linking specific types of SP facilities and services to the possible benefits tenants perceive. Only a limited amount of research has been conducted on the tenants' needs of SP facilities and services (Albahari et al. 2018). Several patterns emerge from the analysis. Proximity of university benefits are attained through the attributes $R \& D$, equipment, training programs, information access and business networking events. Possibly, SP firms interpret these attributes as potential ways for fostering relations with the university. In contrast, only training and information attributes are associated with knowledge benefits. This suggests that SPs should look beyond the primary facilities and services for enabling knowledge benefits between park tenants. When cognitive barriers are considered, Chen et al. (2016) posited that business partners within the same value chain are essential for improved innovation performance, which suggests that preferences for specific partner types exist. In this study, we find that 
SP firms associate proximity of similar firms to research-related facilities and social and business networking events. The former suggests that the shared usage of research-related facilities between firms is not only seen as a way for cost saving, but can also contribute to proximity benefits. The selection of image and prestige of the site was not significantly different compared to the expected distribution of equal chance among benefits. This suggests that image benefits are achieved through the total package of attributes and not just from the way the SP looks.

Second, within this study it is also taken into account that SPs may accommodate a heterogeneous group of firms. Past research has argued the importance of acknowledging the heterogeneous composition of SP firms (Ferguson and Olofsson 2004; Chan and Lau 2005; Díez-Vial and Fernández-Olmos 2015; Ubeda et al. 2019). The cluster analyses show three different SP tenant types based on (dis)similarities on activities, size and length of stay. The average duration of stay of 4.84 years for the cluster located the shortest on a SP, should already provide for a sufficient period for these tenants to actually experience benefits from the SP attributes (Liberati et al. 2016).

The first tenant type, commercially-oriented firms associate attributes more often with proximity of markets and customers than the other two tenant types, which is in line with their weaker focus on research-based activities. This group mainly perceives workspace and networking events as ways to be near their customers. These attributes could ultimately allow tenants to venture in new markets and are especially beneficial for new product development (Van Der Borgh et al. 2012).

The second tenant type, mature science-based firms associate networking events with the proximity of firms more often. Moderately-sized firms are likely to depend on networks due to the absence of market knowledge and new technology or in order to improve their own products (Van De Vrande et al. 2009). Compared to younger firms within the sample, mature firms expected knowledge sharing and collaboration to happen relatively less through training programs. The knowledge of mature firms is more likely to be more explicit than tacit and therefore more exposed to competition (McAdam and McAdam 2008; Díez-Vial and Fernández-Olmos 2017). Stronger associations are found between $R \& D$, training and networking attributes and the proximity benefits; university, customers and firms. Díez-Vial and Fernández-Olmos (2015) argued that firms with more prior experience in collaborating with universities are more likely to benefit from their stay on SPs. The mature science-based firms within the sample have stayed relatively the longest on their SPs, which might explain their positive perception towards the university. However, the effectiveness of knowledge for tenant firms with high absorptive capacity might reduce as a result of knowledge duplicity (Ubeda et al. 2019). Furthermore, Gassmann et al. (2010) suggested that larger firms are motivated to engage in open innovation strategies as a means to be near their markets and to access potential human talent in order to expand their knowledge base. This is further underlined in this study where it is found that mature science-based firms associate training programs (developing human talent) with proximity of customers (improving offering to customer needs) more often than the other two tenant types.

The last tenant type, young technology-based firms, which are smaller and younger, value cost benefits more through their workspaces and image benefits more through social events. These findings are in line with Ferguson and Olofsson (2004) and Clarysse and Bruneel (2007) that besides money, start-ups also seek support in interacting with others and legitimacy. For small and medium-sized enterprises a liability to adopt open innovation 
strategies is their small size, which restricts their management of these processes and may result in less benefits (Gassmann et al. 2010). This could explain why this group is relatively more cost-driven and this would underscore the provision of shared facilities and services on SPs aimed at smaller and younger firms. However, from an R\&D management perspective, Oakey (2007) suggested that some reluctance to collaborate among start-ups on SPs is present, because of confidentiality and competing in similar local markets. In contrast, from a commercial perspective, Heydebreck et al. (2000) suggested that technology-based start-ups are required to seek out global opportunities to launch their innovations in order to break-even from their R\&D expenses, which could partly explain why we find in this study that firms consider business networking events primarily as a way to be near customers. Moreover, the socialisation process among organisations on SPs is beneficial for knowledge sharing as emphasized in Inomata et al. (2016). Compared to the other firm types, young technology-based firms associate cost benefits considerably less often with business support. This could indicate that this group perceives the expenses of these services as a disadvantage, given limited financial resources available (Westhead and Batstone 1999; Chan and Lau 2005).

\section{Conclusion}

This study focused on the benefits that SP tenants perceive from SP attributes related to the facilities and services on park. In order to gain insight in the added value of SP attributes, park tenant representatives were asked how they associate proximity and SP related benefits to the offered SP facilities and services. In a cluster analysis three different tenant types are found based on organisational characteristics. The attribute-benefit associations made by these tenant types were further analysed as SPs cater to a wide range of tenants (Lecluyse et al. 2018). This study contributes to both theory and SP practice. From an academic perspective this study offers additional insights in the further conceptualisation of SP development from the perspective of tenants, which was identified by Mora-Valentín et al. (2018) as a research gap. This study sheds light on what role SP facilities and services play for significantly different tenant types to attain various perceived benefits. Within the Dutch context, SPs are home to a vast range of technology and science-based firms, but also more commercially-oriented counterparts who are more focused on valorising knowledge. Taking into account these different tenant types, different benefits are associated through different SP attributes. For practitioners, this study reveals that there are different needs among tenant types, which are related to perceived benefits that are obtained through specific SP attributes. These needs are studied through the user-side (i.e. the facilities and services) of what a SP offers. SP developers and managers should consider which type of firms they want to target and configure their facilities and services accordingly in order to meet the demands of their target group(s).

The more commercially-oriented firms focus more on being near to their clients. For the other more technology and science-based counterparts image benefits are important. The more mature firms seek ways to be near the university, customers and similar firms, while younger firms are more cost-driven. In this study several (principal) benefits, such 
as proximity of university and proximity of firms, are perceived as important. However, when related to SP attributes these important principal benefits are selected less frequently. This shows that in the perception of park tenants, while SPs could provide these benefits for them, the facilities or services are limited in aiding firms in achieving these organisational goals. Moreover, this study reveals that the added value of SP attributes extends further than simple location-based support (i.e. park management, business support), as training programs and networking services that a SP offers are also perceived as a way to gain knowledge and to be near the university, customers and other firms. A SP providing information access, business networking events and training programs could aid firms in improving their product and service offerings. This implies that policy attention should be given to the design and management of SPs that extend beyond being mere property initiatives, into places that facilitate proximity and potentially innovation.

This study is not without limitations. Firstly, as the sample included only Dutch firms it only gives a limited view on the perception of park tenants in the Netherlands. For this country the results are still difficult to generalise as it only included firms from seven of seventeen eligible SPs and the sample distribution is not representative among these seven SPs. So future research on perceived benefits in relation to SP attributes should be conducted in other countries as well with a more random sample, in order to look for national differences. A second limitation is that this research approach is based on data collection on one moment in time. Díez-Vial and Fernández-Olmos (2017) posited that the value that SPs offer to firms is dynamic in time due to contextual and structural factors. This suggests that more longitudinal work should be done as the perceived benefits of SP attributes are likely to be dynamic. Thirdly, the a priori list of attributes and benefits that was presented to respondents is derived from literature and in order to reduce respondent burden the total number was kept limited. Moreover, the scope of the study is confined to the SP structural attributes, while factors related to location, such as accessibility by public transport or car were not considered. Therefore, it is interesting in future studies to use more open formats that allow to measure attribute-benefit associations based on recall instead of recognition. Finally, the present study only focused on attribute-benefit associations. To measure link strengths as well as weights assigned to benefits, a more rigorous econometric framework as developed in Arentze et al. (2015) and Dellaert et al. (2017) can be considered to contribute to a further understanding of the SP concept.

Open Access This article is distributed under the terms of the Creative Commons Attribution 4.0 International License (http://creativecommons.org/licenses/by/4.0/), which permits unrestricted use, distribution, and reproduction in any medium, provided you give appropriate credit to the original author(s) and the source, provide a link to the Creative Commons license, and indicate if changes were made.

\section{Appendix 1}

See Table 10. 


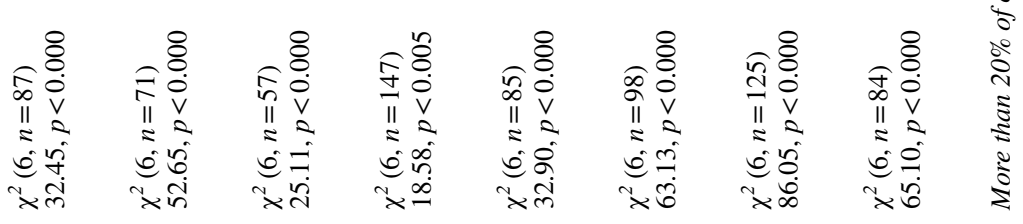

Uे

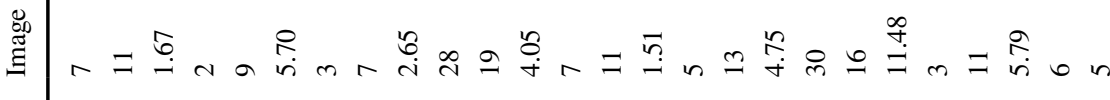

?ํㅡㄹ

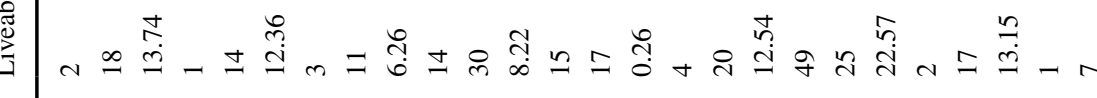

$\bar{P}$

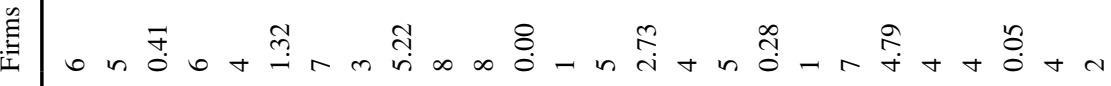

?

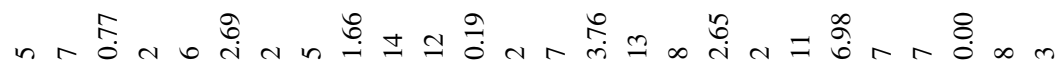

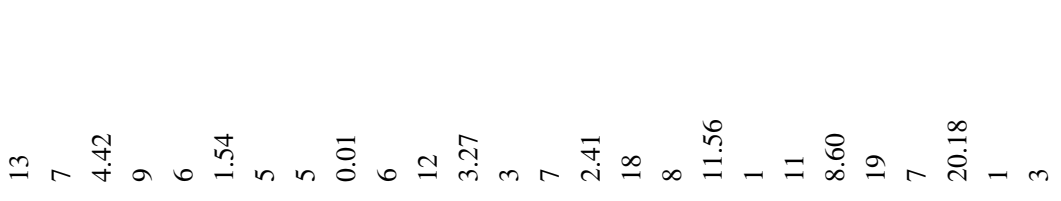

.

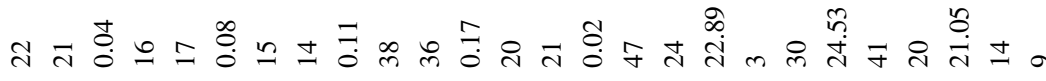

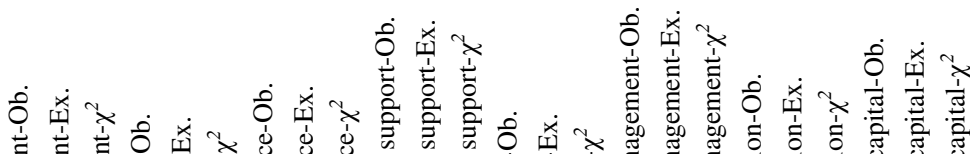

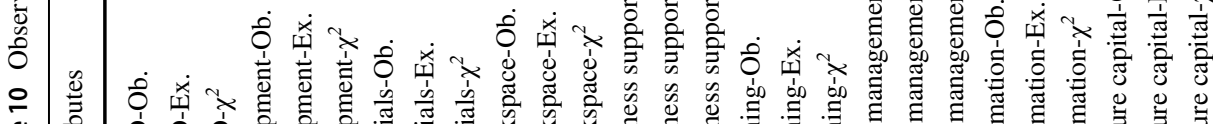

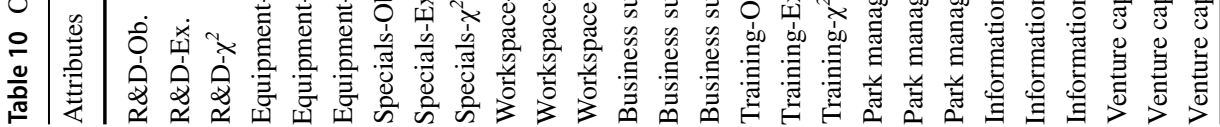




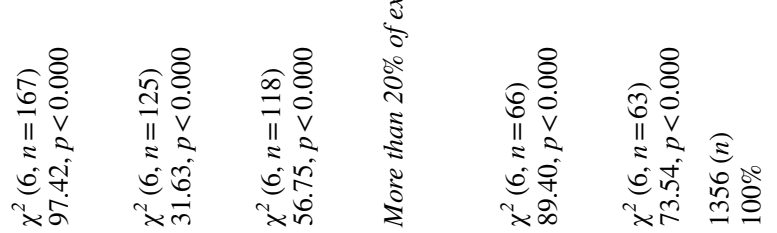

ப்

总

常

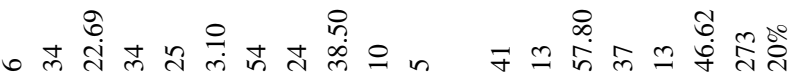

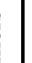

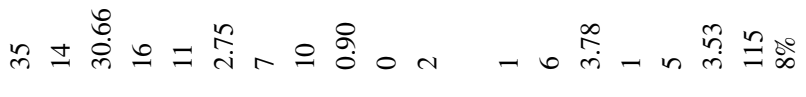

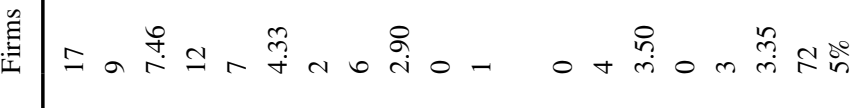

胥

Iㄴㅎํ

$\frac{80}{0}$

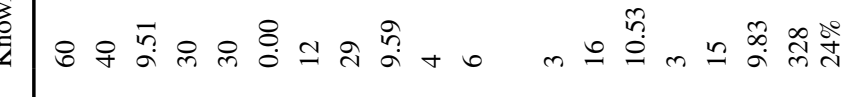

兽

ठิं

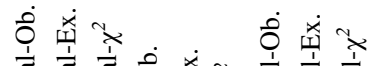

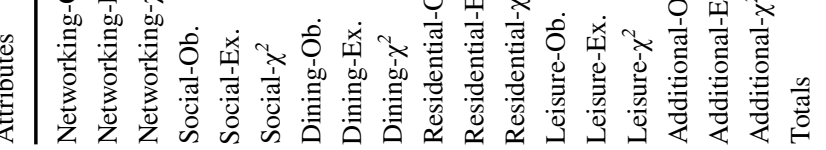




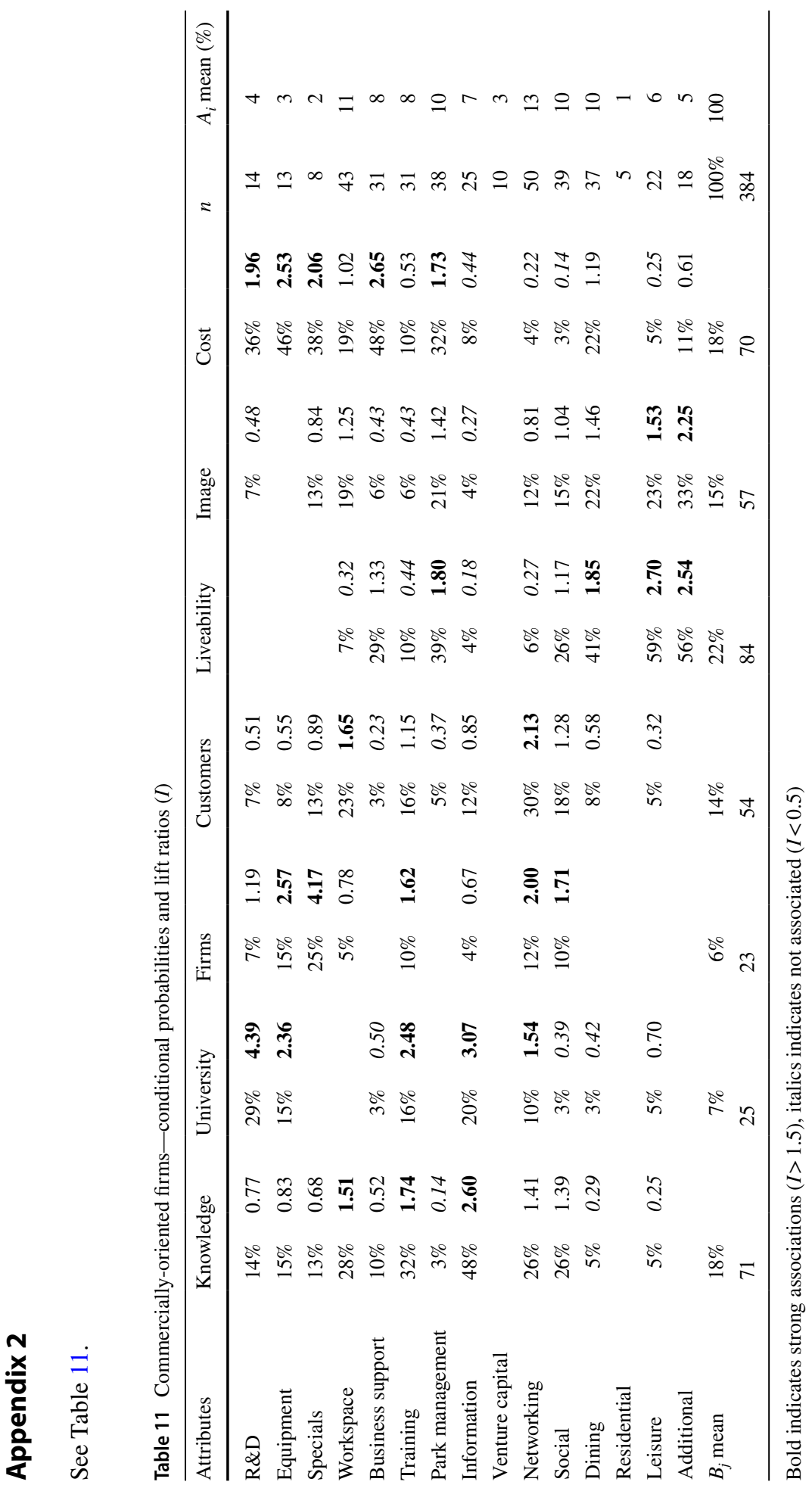




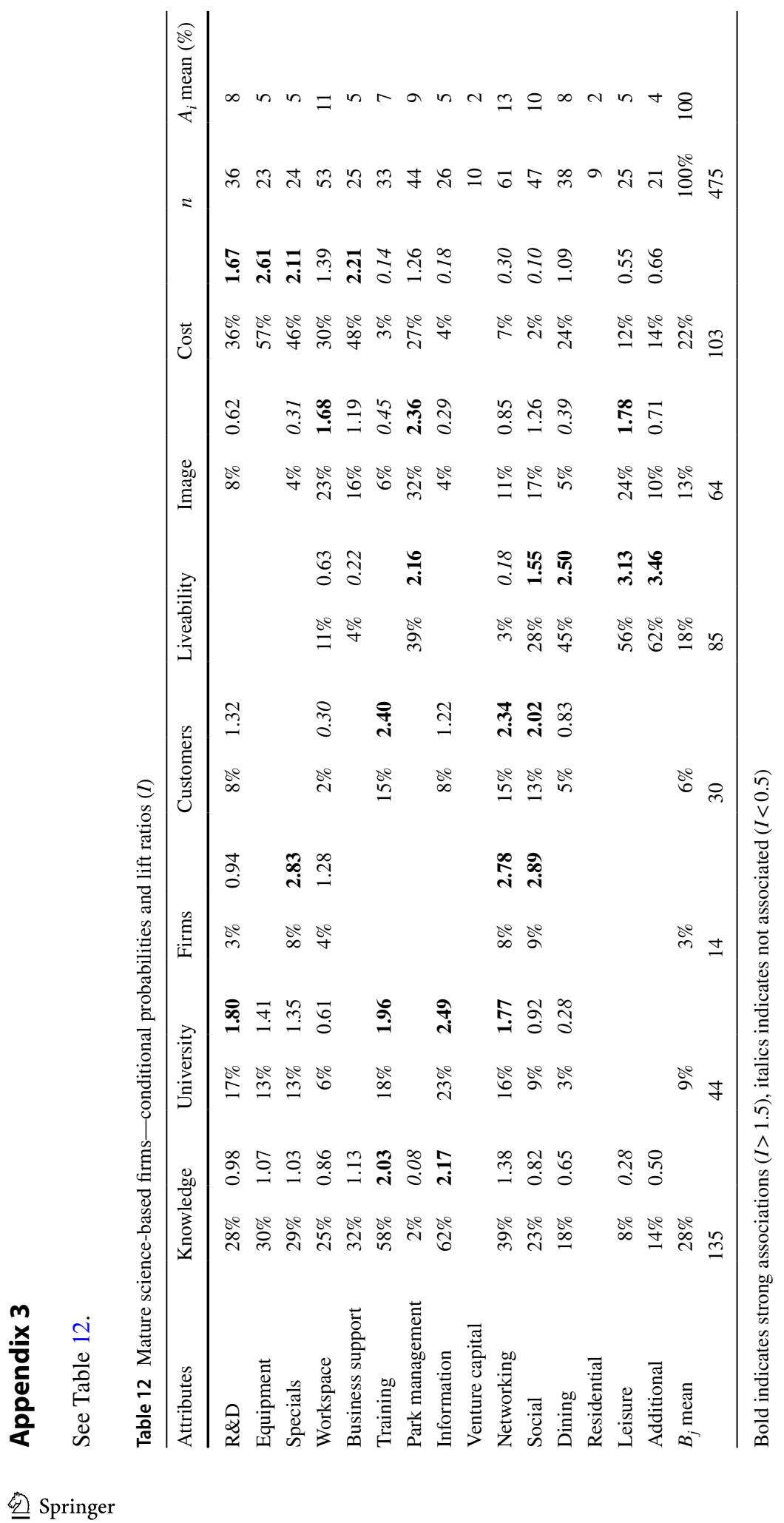




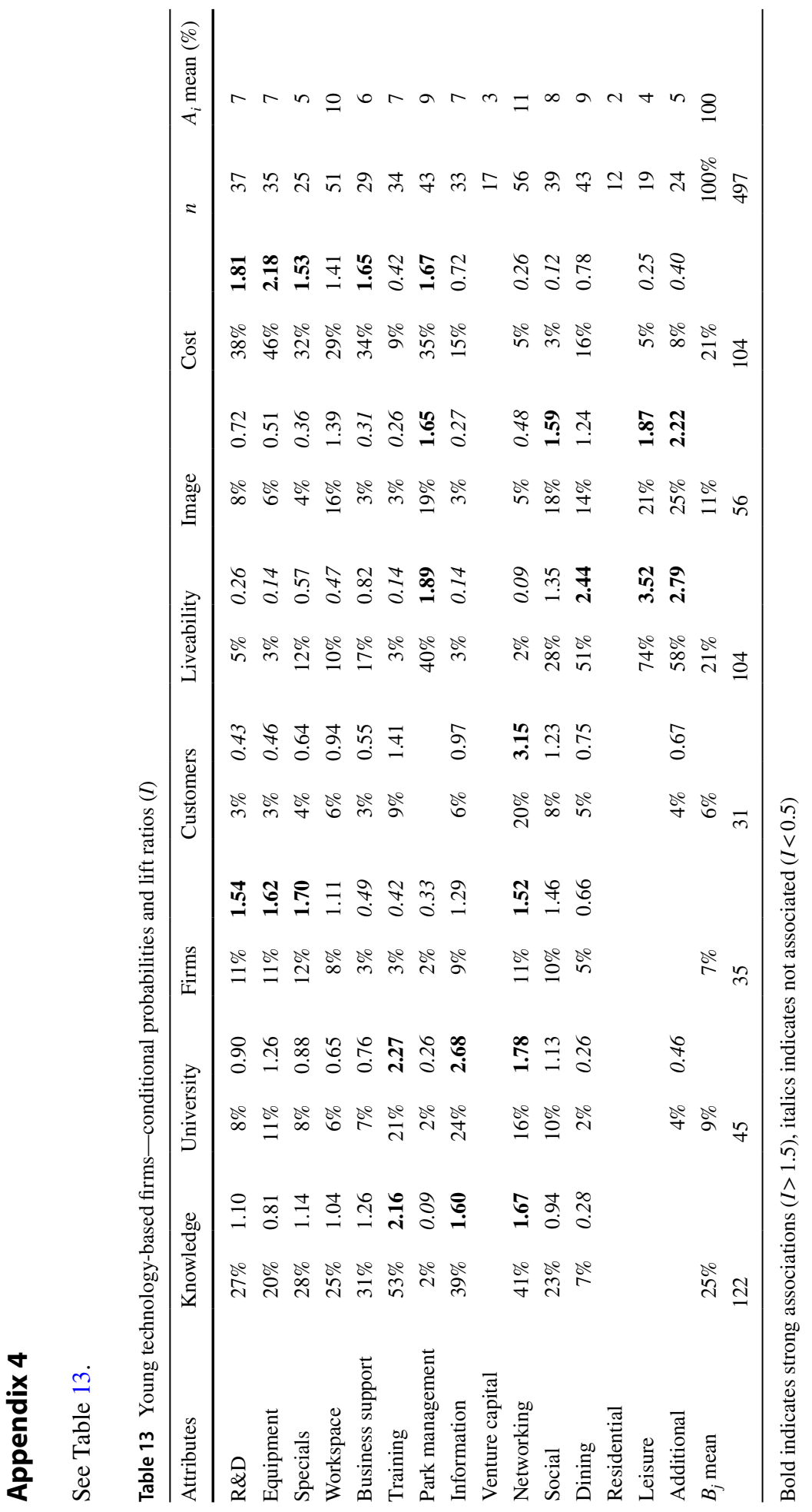




\section{References}

Aaboen, L. (2009). Explaining incubators using firm analogy. Technovation, 29, 657-670. https://doi. org/10.1016/j.technovation.2009.04.007.

Acs, Z. J., Audretsch, D. B., \& Lehmann, E. E. (2013). The knowledge spillover theory of entrepreneurship. Small Business Economics, 41(4), 757-774. https://doi.org/10.1007/s11187-013-9505-9.

Albahari, A., Barge-Gil, A., Pérez-Canto, S., \& Modrego, A. (2016). The influence of science and technology park characteristics on firms' innovation results. Papers in Regional Science, 97(2), 253-279. https ://doi.org/10.1111/pirs.12253.

Albahari, A., Klofsten, M., \& Rubio-Romero, J. C. (2018). Science and technology parks: A study of value creation for park tenants. The Journal of Technology Transfer. https://doi.org/10.1007/s1096 1-018-9661-9.

Albahari, A., Pérez-Canto, S., \& Landoni, P. (2010). Science and technology parks impacts on tenant organisations: A review of literature. MPRA Paper.

Appold, S. (2004). Research parks and the location of industrial research laboratories: An analysis of the effectiveness of a policy intervention. Research Policy, 33(2), 225-243. https://doi.org/10.1016/S0048 -7333(03)00124-0.

Arentze, T. A., Dellaert, B. G. C., \& Chorus, C. G. (2015). Incorporating mental representations in discrete choice models of travel behavior: Modeling approach and empirical application. Transportation Science, 49(3), 577-590. https://doi.org/10.1287/trsc.2013.0513.

Armstrong, J. S., \& Overton, T. S. (1977). Estimating nonresponse bias in mail surveys. Journal of Marketing Research, 14, 396-402.

Audretsch, D. B., \& Lehmann, E. (2006). Location and new venture creation. In S. Parker (Ed.), The life cycle of entrepreneurial ventures (pp. 137-160). New York: Springer. https://doi.org/10.1007/978-0387-32313-8_6.

Bigliardi, B., Dormio, A. I., Nosella, A., \& Petroni, G. (2006). Assessing science parks' performances: Directions from selected Italian case studies. Technovation, 26(4), 489-505. https://doi.org/10.1016/j. technovation.2005.01.002.

Boschma, R. (2005). Proximity and innovation: A critical assessment. Regional Studies, 39(1), 61-74. https ://doi.org/10.1080/0034340052000320887.

Brinkø, R., van Meel, J., \& Nielsen, S. B. (2014). The shared building portfolio: An exploration and typology. In Proceedings of CIB facilities management conference 2014.

Brunswicker, S., \& Vanhaverbeke, W. (2015). Open innovation in small and medium-sized enterprises (smes): External knowledge sourcing strategies and internal organizational facilitators. Journal of Small Business Management, 53(4), 1241-1263. https://doi.org/10.1111/jsbm.12120.

Byosiere, P., Luethge, D. J., Vas, A., \& Salmador, M. P. (2010). Diffusion of organisational innovation: Knowledge transfer through social networks. International Journal of Technology Management, 49(4), 401-420. https://doi.org/10.1504/IJTM.2010.030166.

Capello, R., \& Morrison, A. (2009). Science parks and local knowledge creation: A conceptual approach and an empirical analysis in two Italian realities. In C. Karlsson, A. E. Andersson, P. C. Cheshire, \& R. R. Stough (Eds.), New directions in regional economic development (pp. 267-290). Berlin: Springer. https://doi.org/10.1007/978-3-642-01017-0_13.

Chan, K. F., \& Lau, T. (2005). Assessing technology incubator programs in the science park: The good, the bad and the ugly. Technovation, 25, 1215-1228. https://doi.org/10.1016/j.technovation.2004.03.010.

Chan, K. Y., Oerlemans, L., \& Pretorius, M. W. (2010). Knowledge exchange behaviours of science park firms: The innovation hub case. Technology Analysis \& Strategic Management, 22(2), 207-228. https ://doi.org/10.1080/09537320903498546.

Chen, Y., Vanhaverbeke, W., \& Du, J. (2016). The interaction between internal capabilities and external knowledge sourcing: An empirical study of Chinese firms. R\&D Management, 46(S3), 1006-1023. https://doi.org/10.1111/radm.12162.

Clarysse, B., \& Bruneel, J. (2007). Nurturing and growing innovative start-ups: The role of policy as integrator. $R \& D$ Management, 37(2), 139-149. https://doi.org/10.1111/j.1467-9310.2007.00463.x.

Cohen, W. M., \& Levinthal, D. A. (1990). Absorptive capacity: A new perspective on learning and innovation. Administrative Science Quarterly, 35(1), 128-152.

Colley, K., Brown, C., \& Montarzino, A. (2017). Understanding knowledge workers' interactions with workplace greenspace: Open space use and restoration experiences at urban-fringe business sites. Environment and Behavior, 49(3), 314-338. https://doi.org/10.1177/0013916516629194.

Cummings, J. L., \& Teng, B. S. (2003). Transferring R\&D knowledge: The key factors affecting knowledge transfer success. Journal of Engineering and Technology Management, 20, 39-68. https://doi. org/10.1016/S0923-4748(03)00004-3. 
Dabrowska, J. (2016). Measuring the success of science parks by means of a performance measurement system. In Proceedings of the 33rd IASP world conference on science parks and areas of innovation 2016.

Dahan, E., \& Hauser, J. R. (2002). Product development-Managing a dispersed process. In B. Weitz \& R. Wensley (Eds.), Handbook of marketing (pp. 179-222). London: SAGE.

Dellaert, B. G. C., Arentze, T. A., \& Horeni, O. (2014). Tourists' mental representation of complex travel decision problems. Journal of Travel Research, 53(1), 3-11. https://doi.org/10.1177/00472 87513506297.

Dellaert, B. C. G., Arentze, T. A., Horeni, O., \& Timmermans, H. J. P. (2017). Deriving attribute utilities from mental representations of complex decisions. Journal of Choice Modeling, 22, 24-38. https://doi.org/10.1016/j.jocm.2016.12.001.

Dettwiler, P., Lindelöf, P., \& Löfsten, H. (2006). Utility of location: A comparative survey between small new technology-based firms located on and off science parks-Implications for facilities management. Technovation, 26, 506-517. https://doi.org/10.1016/j.technovation.2005.05.008.

Díez-Vial, I., \& Fernández-Olmos, M. (2015). Knowledge spillovers in science and technology parks: How can firms benefit most? The Journal of Technology Transfer, 40, 70-84. https://doi. org/10.1007/s10961-013-9329-4.

Díez-Vial, I., \& Fernández-Olmos, M. (2017). The effect of science and technology parks on a firm's performance: A dynamic approach over time. Journal of Evolutionary Economics, 27(3), 423-434. https://doi.org/10.1080/09537325.2016.1274390.

Edler, J., \& Georghiou, L. (2007). Public procurement and innovation-Resurrecting the demand side. Research Policy, 36, 949-963. https://doi.org/10.1016/j.respol.2007.03.003.

Etzkowitz, H., \& Zhou, C. (2017). Innovation incommensurability and the science park. R\&D Management, 48(1), 73-87. https://doi.org/10.1111/radm.12266.

European Commission. (2013). Setting up, managing and evaluating EU science and technology parks: An advice and guidance report on good practice. Brussels: Regional and Urban Policy.

Ferguson, R., \& Olofsson, C. (2004). Science parks and the development of NTBFs-Location, survival and growth. The Journal of Technology Transfer, 29(1), 5-17. https://doi.org/10.1023/ B:JOTT.0000011178.44095.cd.

Ferrara, M., Lamperti, F., \& Mavilia, R. (2015). Looking for best performers: A pilot study towards the evaluation of science parks. Scientometrics, 106(2), 717-750. https://doi.org/10.1007/s1119 2-015-1804-2.

Formann, A. K. (1984). Die Latent-Class-Analyse: Einführung in die Theorie und Anwendung. Weinheim: Beltz.

Fukugawa, N. (2006). Science parks in Japan and their value-added contributions to new technology-based firms. International Journal of Industrial Organization, 24(2), 381-400. https://doi. org/10.1016/j.ijindorg.2005.07.005.

Fukugawa, N. (2013). Heterogeneity among science parks with incubators as intermediaries of research collaborations between startups and universities in Japan. International Journal of Technology Transfer and Commercialisation, 12(4), 231-262. https://doi.org/10.1504/IJTTC.2013.071355.

Gassmann, O., Enkel, E., \& Chesbrough, H. (2010). The future of open innovation. R\&D Management, 40(3), 213-221. https://doi.org/10.1111/j.1467-9310.2010.00605.x.

Gilchrist, K., Brown, C., \& Montarzino, A. (2015). Workplace settings and wellbeing: Greenspace use and views contribute to employee wellbeing at peri-urban business sites. Landscape and Urban Planning, 138, 32-40. https://doi.org/10.1016/j.landurbplan.2015.02.004.

Gilsing, V., Nooteboom, B., Vanhaverbeke, W., Duysters, G., \& van der Oord, A. (2008). Network embeddedness and the exploration of novel technologies: Technological distance, betweenness centrality and density. Research Policy, 37, 1717-1731. https://doi.org/10.1016/j.respol.2008.08.010.

Hansen, M. T. (1999). The search-transfer problem: The role of weak ties in sharing knowledge across subunits organization. Administrative Science Quarterly, 44, 82-111.

Heydebreck, P., Klofsten, M., \& Maier, J. C. (2000). Innovation support for new technology-based firms: The Swedish Teknopol approach. R\&D Management, 30(1), 89-100. https://doi.org/10.1111/14679310.00160 .

Hobbs, K. G., Link, A. N., \& Scott, J. T. (2017). Science and technology parks: An annotated and analytical literature review. The Journal of Technology Transfer, 42(4), 957-976. https://doi.org/10.1007/ s10961-016-9522-3.

Inomata, D. O., Costa, E., Mazzaroto, C. S., Barros, A. C., \& Soares, A. L. (2016). Knowledge sharing in industrial associations and science and technology parks. In Proceedings of the 17th working conference on virtual enterprises (PRO-VE). https://doi.org/10.1007/978-3-319-45390-3_6.

Jaffe, A. B. (1989). Real effects of academic research. The American Economic Review, 79(5), 957-970. 
Jahncke, H., Hygge, S., Halin, N., Green, A. M., \& Dimberg, K. (2011). Open-plan office noise: Cognitive performance and restoration. Journal of Environmental Psychology, 31(4), 373-382. https:// doi.org/10.1016/j.jenvp.2011.07.002.

Kharabsheh, R. (2012). Critical success factors of technology parks in Australia. International Journal of Economics and Finance, 4(7), 57-66. https://doi.org/10.5539/ijef.v4n7p57.

Koçak, O., \& Can, O. (2014). Determinants of inter-firm networks among tenants of science technology parks. Industrial and Corporate Change, 23(2), 467-492. https://doi.org/10.1093/icc/dtt015.

Lecluyse, L., Knockaert, M., \& Spithoven, A. (2018). The contribution of science parks: A literature review and future research agenda. The Journal of Technology Transfer. https://doi.org/10.1007/ s10961-018-09712-x.

Lee, D. S., \& O’Huallachain, B. (2012). Spatial, network-based and regional proximity in US biotechnology. In M. Van Geenhuizen \& P. Nijkamp (Eds.), Creative knowledge cities: Myths, visions and realities (pp. 303-332). Cheltenham: Edward Elgar Publishing Ltd.

Liberati, D., Marinucci, M., \& Tanzi, G. M. (2016). Science and technology parks in Italy; main features and analysis of their effects on the firms hosted. The Journal of Technology Transfer, 41, 649-729. https://doi.org/10.1007/s10961-015-9397-8.

Lindelöf, P., \& Löfsten, H. (2003). Science park location and new technology-based firms in Sweden Implications for strategy and performance. Small Business Economics, 20(3), 245-258. https://doi. org/10.1023/A:1022861823493.

Link, A. N., \& Link, K. R. (2003). On the growth of U.S. Science Parks. Journal of Technology Management and Innovation, 28, 81-85. https://doi.org/10.1023/A:1021634904546.

Link, A. N., \& Scott, J. T. (2003). U.S. science parks: The diffusion of an innovation and its effects on the academic missions of universities. International Journal of Industrial Organization, 21(9), 13231356. https://doi.org/10.1016/S0167-7187(03)00085-7.

Link, A. N., \& Scott, J. T. (2015). Research, science, and technology parks: Vehicles for technology transfer. In A. N. Link, D. Siegel, \& M. Wright (Eds.), The Chicago handbook of university technology transfer (pp. 168-187). Chicago: University of Chicago Press.

Löfsten, H. (2016). New technology-based firms and their survival: The importance of business networks, and entrepreneurial business behaviour and competition. Local Economy, 31(3), 393-409. https://doi.org/10.1177/0269094216637334.

McAdam, M., \& McAdam, R. (2008). High tech start-ups in university science park incubators: The relationship between the start-up's lifecycle progression and use of the incubator's resources. Technovation, 28, 277-290. https://doi.org/10.1016/j.technovation.2007.07.012.

Monck, C., \& Peters, K. (2009). Science parks as an instrument of regional competitiveness: Measuring success and impact. In Proceedings of IASP 2009 annual conference.

Mooi, E., \& Sarstedt, M. (2014). A concise guide to market research: The process, data, and methods using IBM SPSS Statistics (2nd ed.). Berlin: Springer. https://doi.org/10.1007/978-3-642-12541-6.

Mora-Valentín, E. M., Ortiz-de-Urbina-Criado, M., \& Nájera-Sánchez, J. J. (2018). Mapping the conceptual structure of science and technology parks. The Journal of Technology Transfer, 43(5), 14101435. https://doi.org/10.1007/s10961-018-9654-8.

National Research Council. (2009). Understanding research, science and technology parks: Global best practices. In Report of a symposium. National Academies Press.

Ng, W. K. B., Appel-Meulenbroek, H. A. J. A., Cloodt, M. M. A. H., \& Arentze, T. A. (2019). Towards a segmentation of science parks: A typology study on science parks in Europe. Research Policy, 48(3), 719-732. https://doi.org/10.1016/j.respol.2018.11.004.

Norušis, M. (2011). Cluster analysis. IBM SPSS statistics 19 statistical procedures companion (pp. 375404). Upper Saddle River: Prentice Hall.

Oakey, R. (2007). Clustering and the R\&D management of high-technology small firms: In theory and practice. $R \& D$ Management, 37(3), 237-248. https://doi.org/10.1111/j.1467-9310.2007.00472.x.

Oseland, N. (2009). The impact of psychological needs on office design. Journal of Corporate Real Estate, 11(4), 244-254. https://doi.org/10.1108/14630010911006738.

Romijn, H., \& Albu, M. (2002). Innovation, networking and proximity: Lessons from small high technology firms in the UK. Regional Studies, 1, 81-86. https://doi.org/10.1080/00343400120099889.

Rosenkopf, L., \& Almeida, P. (2003). Overcoming local search through alliances and mobility. Management Science, 49(6), 683-837. https://doi.org/10.1287/mnsc.49.6.751.16026.

Storper, M., \& Venables, A. J. (2004). Buzz: Face-to-face contact and the urban economy. Journal of Economic Geography, 4, 351-370. https://doi.org/10.1093/jnlecg/lbh027.

Tan, P. N., Steinbach, M., Kumar, V., \& Karpatne, A. (2006). Introduction to data mining. Boston: Pearson Addison Wesley. 
Ter Hofstede, F., Audenaert, A., Steenkamp, J. E. M., \& Wedel, M. (1998). An investigation into the association pattern technique as a quantitative approach to measuring means-end chains. International Journal of Research in Marketing, 15(1), 37-50.

Tkaczynski, A. (2017). Segmentation using two-step cluster analysis. In T. Dietrich, S. Rundle-Thiele, \& K. Kubacki (Eds.), Segmentation in social marketing: Process, methods and application (pp. 109-125). Singapore: Springer. https://doi.org/10.1007/978-981-10-1835-0.

Ubeda, F., Ortiz-de-Urbina-Criado, M., \& Mora-Valentin, E. M. (2019). Do firms located in science and technology parks enhance innovation performance? The effect of absorptive capacity. The Journal of Technology Transfer, 44(1), 21-48. https://doi.org/10.1007/s10961-018-9686-0.

Van De Vrande, V., De Jong, J. P. J., Vanhaverbeke, W., \& De Rochemont, M. (2009). Open innovation in SMEs: Trends, motives and management challenges. Technovation, 29(6-7), 423-437. https://doi. org/10.1016/j.technovation.2008.10.001.

Van Der Borgh, M., Cloodt, M., \& Romme, G. L. (2012). Value creation by knowledge-based ecosystems: Evidence from a field study. R\&D Management, 42(2), 150-169. https://doi.org/10.111 1/j.1467-9310.2011.00673.x.

Van Der Klundert, M., \& Van Winden, W. (2008). Creating environments for working in a knowledge economy: Promoting knowledge diffusion through area based development. Corporations and Cities, paper 09.

Van Dierdonck, R., Debackere, K., \& Rappa, M. A. (1991). An assessment of science and technology parks: Towards a better understanding of their role in the emergence of new technologies. R\&D Management, 21(2), 109-123. https://doi.org/10.1111/j.1467-9310.1991.tb00741.x.

Van Winden, W., \& Carvalho, L. (2015). Synergy management at knowledge locations. In J. T. Miao, P. Benneworth, \& N. A. Phelps (Eds.), Making 21st century knowledge complexes: Technopoles of the world revisited (pp. 62-81). London: Routledge.

Villasalero, M. (2014). University knowledge, open innovation and technological capital in Spanish science parks: Research revealing or technology selling. Journal of Intellectual Capital, 15(4), 479-496. https ://doi.org/10.1108/JIC-07-2014-0083.

Wang, B., \& Adolphe, L. (2012). Spirit of place in science park. Take ZJ Inno-Park as an example. In Proceedings of international congress on ambiances (pp. 551-556).

Westhead, P., \& Batstone, S. (1999). Perceived benefits of a managed science park location. Entrepeneurship Regional Development, 11(2), 129-154. https://doi.org/10.1080/089856299283236.

Yang, C., Motohashi, K., \& Chen, J. (2009). Are new technology-based firms located on science parks really more innovative? Evidence from Taiwan. Research Policy, 38, 77-85. https://doi.org/10.1016/j.respo 1.2008.09.001.

Zhang, Y. H. (2002). A developing economy oriented model for science park management. Doctor of Philosophy thesis. Center for Research Policy, University of Wollongong. http://ro.uow.edu.au/theses/989.

Publisher's Note Springer Nature remains neutral with regard to jurisdictional claims in published maps and institutional affiliations. 